\title{
Estudio de la práctica fotográfica en Cusco en el período de 1897 a 1920
}

\section{Study of the photographic practice in Cusco in the period from} 1897 to 1920

\author{
Andrés Garay \\ Universidad de Piura, Perú \\ andres.garay@udep.edu.pe \\ https://orcid.org/0000-0002-8423-2751
}

\section{Resumen:}

Se propone un estudio de la fotografía cusqueña entre 1897 y 1920 , período del que se tiene conocimiento parcial de la actividad fotográfica en esta ciudad andina. Aun cuando los archivos de los fotógrafos de este período están perdidos o no han aparecido hasta la fecha, y aun ante la escasa bibliografía, se procurará precisar acerca de su dinámica comercial y creativa y sobre la relación que pudieron haber tenido entre ellos y con el contexto sociocultural en los años acotados. Se ha empleado una metodología cualitativa con enfoque interpretativo de documentos de época y diseño narrativo para poder hilvanar la información acopiada, con el objetivo de conocer cómo fue el desarrollo de la fotografía en Cusco hasta 1920, año de la llegada del fotógrafo Martín Chambi a esta ciudad. En el estudio, se detecta la actividad de varios fotógrafos, el alcance profesional de sus trabajos en la esfera pública, la oferta de postales y vistas para el turismo, la relación entre proyectos científicos y fotografía, y otros aspectos.

\begin{abstract}
:
A study of Cusco photography between 1897 and 1920 is proposed, a period of which there is partial knowledge of the photographic activity in this Andean city. Even though the archives of the photographers of this period are lost or have not appeared to date, and even given the limited bibliography, an attempt will be made to specify about their commercial and creative dynamics and the relationship they may have had between them and with the sociocultural context in limited years. A qualitative methodology has been used with an interpretive approach to period documents and narrative design to be able to string together the information collected, with the aim of knowing how the development of photography was in Cusco until 1920, the year of the arrival of the photographer Martín Chambi to this city. The study detects the activity of many photographers, the professional scope of their work in the public sphere, the offer of postcards and views for tourism, the relationship between scientific projects and photography, and other aspects.
\end{abstract}

Palabras clave: Cusco; fotografía; Max T. Vargas; Miguel Chani; Martín Chambi; postal.

Keywords: Cusco; photography; Max T. Vargas; Miguel Chani; Martín Chambi; postcard. 


\section{Introducción}

El marco temporal de esta propuesta tiene dos hitos. El primero es la "Exposición General Departamental” de Cusco acaecida en 1897, evento en el que fotógrafos foráneos, como el arequipeño Max T. Vargas, presentaron obras que fueron premiadas y que recibieron el favor del público y de la crítica periodística local. La obra y actividad de Vargas ocupó un lugar importante en ese contexto, y en los años sucesivos su influencia fue decisiva en el desarrollo de la fotografía en el sur andino peruano.

El segundo hito es el artículo "El Cuzco: Meca del Turismo de la América del Sur", producido en 1920 pero publicado en 1921 con importante resonancia pública en el sur andino peruano, en el que se nombra a los fotógrafos profesionales activos en la ciudad; entre ellos, el recién llegado Martín Chambi. Fotógrafo de origen indígena, Chambi debutaba en Cusco tras haberse formado en los estudios fotográficos más importantes de Arequipa - en el de Max T. Vargas, primero, y en el estudio de los Vargas Hermanos, luego- bajo el modelo de fotógrafo profesional. Se podría decir que él se insertó en una cultura fotográfica existente en Cusco.

La actividad fotográfica en Cusco entre 1897 y 1920 estuvo marcada por la presencia de profesionales de estudio, como es el caso de Miguel Chani, que daban servicios de retratos y producían y vendían postales y vistas de motivos andinos, tal como actuaban otros fotógrafos en otras ciudades andinas, como La Paz y Quito.

También se ha identificado la práctica de aficionado y el uso de la fotografía en arqueólogos y expedicionarios. Durante este período, se empezó a considerar lo indio y lo incaico como temas de discusión en la academia local, en coincidencia con el hallazgo, en 1911, de Machu Picchu, lugar que representó el símbolo de una historia e identidad propias.

Interesa, por tanto, conocer con más precisión las características de la actividad fotográfica en Cusco, sus principales autores y las relaciones que pudieron haber existido entre los fotógrafos en el rango de tiempo planteado.

\section{Marco teórico y metodología}


En los últimos veinte años, se ha señalado en diferentes artículos académicos y divulgativos la existencia de una escuela de fotografía cusqueña, en alusión a la presencia y actividad de diversos fotógrafos en esta ciudad. Por ejemplo, la investigadora Adelma Benavente García (2000) definió "The Cusco School" [la escuela cusqueña] tan solo con las breves biografías de Miguel Chani, Juan Manuel Figueroa Aznar, José Gabriel González, Martín Chambi, Filiberto y Crisanto Cabrera, y Avelino Ochoa, y los consideró como los fotógrafos más importantes de inicios del siglo XX hasta 1930.

La referencia a la escuela cusqueña de fotografía se ha hecho una constante, a pesar de que las posibles influencias o conocimientos transmitidos de maestros a discípulos no han sido hallados ni documentados debidamente. La escuela cusqueña, según Nieto, "es el término que los especialistas han acuñado para agrupar a esos más de veinte fotógrafos que trabajaron en Cuzco en la primera mitad del siglo XX" (2008, p. 12).

En la I Bienal de Fotografía de Cusco de 2017, se incluyó una exposición de fotografía histórica con casi los mismos fotógrafos mencionados anteriormente, los cuales pertenecían a la "bien llamada Escuela Cusqueña de Fotografía" (Gutiérrez, 2017, p. 2). La nominación funciona para localizar a los fotógrafos cusqueños activos en las primeras décadas del siglo $\mathrm{XX}$, a modo de directorio, pero no establece necesariamente influencias entre ellos o que las hayan recibido de otros fotógrafos locales o de otras ciudades.

Evitando nombrar la "escuela cusqueña de fotografía", Hiatt señala que en Cusco ya se había utilizado la cámara desde fines del siglo XIX para "comprender la identidad de la sierra y hacer que la región y sus habitantes fueran consumibles por públicos más amplios” (2015, p. 298). Por su parte, Majluf apunta que el tema indígena en fotografía había sido abordado antes de 1920 por Max T. Vargas, por Luis Gismondi y por los editores limeños Eduardo Polack y Luis Sablich, de modo que incorpora nuevos nombres (Majluf, 2015, p. 278). Para Hiatt, Miguel Chani es el fotógrafo "estrella" de la primera generación de fotógrafos activos en Cusco, pues fotografió desde 1908 eventos históricos, sitios arqueológicos, indígenas y fue colaborador de la revista limeña Variedades en 1910 (2015, p. 298).

El impulso del turismo arqueológico representó una alternativa comercial muy importante para los fotógrafos profesionales, pero hubo otras prácticas 
fotográficas. Una de ellas estuvo relacionada con los trabajos arqueológicos, de los cuales el más emblemático fue el hallazgo de Machu Picchu en 1911, encabezado por el estadounidense Hiram Bingham, quien fotografió toda la exploración. Por su parte, el arqueólogo alemán Max Uhle lo antecedió en el uso de la cámara en los trabajos de excavación en Cusco a inicios del siglo XX. Uhle, además, cultivó la afición del coleccionismo fotográfico adquiriendo imágenes cusqueñas y del sur andino peruano en el estudio arequipeño de Max T. Vargas, fotografías que intercambiaba con sus colegas científicos.

Es innegable que la obra de Martín Chambi es la que ha generado la mayor cantidad de publicaciones en los últimos treinta años en catálogos, libros y revistas científicas y de divulgación, gracias a la calidad de su fotografía y también por la existencia de su archivo fotográfico. La pérdida de archivos de sus contemporáneos ha limitado las investigaciones, especialmente en los años anteriores a su llegada a Cusco en 1920, cuando, según Hiatt, existía una "cultura fotográfica ya floreciente" (2015, p. 298). Además, los datos biográficos de los fotógrafos cusqueños de estos años son escasos, como acusan Trevisan y Massa (2009, p. 48).

Bajo una metodología cualitativa con enfoque interpretativo a partir de documentos y publicaciones de época, revisados en la hemeroteca de la Biblioteca Municipal del Cusco, este estudio pretende, a modo de línea de tiempo básica y orgánica, identificar y relacionar información específica sobre los fotógrafos y sus actividades en Cusco entre 1897 y 1920, en un contexto en el que se generaron expectativas y discursos en torno a la temática histórica, indígena y arqueológica.

\section{La "Exposición General Departamental" de Cusco de 1897 y la figura de Max T. Vargas}

Las autoridades cusqueñas, encabezadas por el prefecto Pedro Carrión, organizaron una exposición en julio de 1897 con la finalidad de poner en valor las riquezas cusqueñas. La exposición se concibió como una expresión de progreso ante el nuevo siglo a través de la riqueza que podían mostrar los cusqueños de toda la región. Se trató de un evento al que estuvieron invitados "hacendados, industriales, artesanos, fabricantes, etc." (Exposición Industrial, 1896). 
Al inicio de ese año, se ha identificado activo en Cusco al fotógrafo Jacinto Gismondi - hermano de L. D. Gismondi- con su "Fotografía Artística" (J. Gismondi y Ca, 1897), en cuyo aviso publicitario indicaba que había reabierto su establecimiento en la calle Santa Catalina, 91, y ofrecía máquinas fotográficas, aparatos y materiales finos. En las semanas siguientes, Gismondi daba a conocer que estaba preparando "una galería de cuadros" (Fotografía, 1897a) de los principales monumentos del Perú para ser presentados en la exposición. Otro fotógrafo activo a inicios de año fue Luis Alviña, quien, ubicado en la calle Matará, 125, se daba a conocer como uno de los mejores de Europa y Norteamérica (Fotografía, 1897b).

Por su parte, Arturo Ramírez anunciaba que estaba "de regreso de la ciudad de Arequipa [...] cuyos trabajos fotográficos son muy conocidos y dignos de recomendarse" (Fotógrafo, 1897a); ofrecía también "instantógrafos [sic] para retratar criaturas desde un mes de edad" en su estudio temporal de la calle San Andrés (Ramírez, 1897).

En el programa oficial de la "Exposicion General Departamental", publicado en marzo de 1897, se presentaban grandes series temáticas, como productos naturales, ciencias y letras, inmigración, antigüedades, industria y artes liberales, flora y fauna, entre otras, desglosadas en secciones específicas (Programa para la Exposición General Departamental, 1897). La quinta serie correspondía a bellas artes y tenía secciones de "Literatura", "Dibujo", "Pintura", "Música” y "Fotografía". A los fotógrafos se los invitaba a exponer sus aparatos e instrumentos, fotografías impresas -sobre papel, vidrio, tela, etc.-, fotograbados, fotolitografía, ferrotipos y restauraciones de pinturas antiguas.

La exposición se realizó el 28 de julio de ese año y, cuando todavía no se habían publicado los premios, una noticia de periódico hizo referencia al fotógrafo Max T. Vargas, a quien se le reconocía la calidad de las diversas fotografías que presentó y también los retratos que hizo a unos nativos amazónicos que habían sido llevados a la exposición desde la provincia cusqueña de La Convención. Se informaba que Vargas había llegado de Arequipa y que era "un artista completo en su profesión como lo ha probado en lo dicho, por lo que lo recomendamos al público a fin de que aproveche de su corta estadía por acá" (Fotógrafo, 1897b). No hubo noticias o comentarios similares sobre otros fotógrafos. 
Max T. Vargas volvió a ser reconocido en un editorial periodístico por sus fotografías en porcelana y por los retratos hechos al presidente Nicolás de Piérola y al prefecto Pedro Carrión (Editorial, 1897). Este texto también remarcó la calidad de las fotografías de Luis Alviña. En las semanas siguientes, se publicó la lista de premios: medalla de plata - no hubo medalla de oro- a Max T. Vargas y a Luis Alviña por sus "trabajos fotográficos", y a Arturo Ramírez por sus fotografías "retocadas al carbón” y sus retratos del coronel Pedro Carrión y Baltazar Latorre (Premios, 1897). El reconocimiento público fue significativo para afianzar el prestigio profesional de los fotógrafos y la valoración de la fotografía en la esfera pública cusqueña.

Desde la ciudad de Arequipa, un diario afirmó que la exposición había sido un hito en la historia de Cusco por la vasta expresión de progreso a través de lo que era capaz de producir el hombre andino en el arte, el trabajo y la industria (El Cuzco y su exposición industrial, 1897).

A pesar de que el archivo fotográfico de Max T. Vargas está perdido, la importancia de su obra en su época, tanto en Cusco como en Arequipa, se hace evidente en las informaciones periodísticas. Este joven fotógrafo -tendría 24 años de edad y en 1896 había fundado su estudio fotográfico en Arequipaestuvo en Cusco en 1897 desde que se inauguró la exposición, es decir, desde julio hasta octubre de ese mismo año (Villacorta \& Garay, 2017). Al final de su estancia, una noticia volvió a referirse a su trabajo de retrato y a las distintas técnicas que aplicaba, entre ellas el sistema de porcelanotipo. La noticia alentaba al público a acudir al estudio temporal de Max T. Vargas en Cusco para obtener "buenos retratos" porque "dentro de breve tiempo se retira de esta ciudad" (Fotógrafo, 1897c).

Durante los meses que vivió en Cusco, Vargas alternó su trabajo en la ciudad con recorridos por el interior de la región, donde fotografiaba, con estética correcta y ordenada, los sitios arqueológicos a los que se podía acceder, como Rajchi, Písac, Ollantaytambo o Sacsayhuaman. Su interés documental fue amplio: registró también monumentos coloniales, vistas panorámicas y calles de la ciudad de Cusco, tipos - mujeres y hombres indígenas- y costumbres; creó un repertorio de imágenes. A su regreso de Arequipa, procesó esta producción en formatos de tarjetas postales y vistas, y las ofrecía, en inglés y español, en las vitrinas de su local al viajero, científico o turista. Como señala Buchholz, estas 
actividades fotográficas de Vargas contribuyeron a formar una "nueva imagen del Perú”, basada en un creciente interés en la historia y la arqueología (2015, p. 43). Creó interesantes series fotográficas de Tiahuanaco, Cusco, La Paz y Arequipa, muchas de las cuales mandó a imprimir a Alemania.

Vargas entroncaría en lo que Navarrete identifica en otros lugares de América Latina como proyectos de archivo fotográfico, "entendiéndose éste como procedimiento cultural de registro, ordenamiento, clasificación y valorización en sus contextos de la vida social y sus diferentes prácticas mediante el uso de la fotografía” (Navarrete, 2009/2017, p. 48). En ese sentido, en La Paz (Bolivia), L. D. Gismondi o Julio Cordero podrían ser fotógrafos parecidos a Vargas en su quehacer profesional, aunque fue Gismondi, que se estableció en esta ciudad en 1904, después de recorrer el sur peruano con sus hermanos con estudios itinerantes, quien, según Querejazu Leyton, se "adhirió a este proceso comercial de edición y difusión de postales" (2009, p. 16).

Otro contemporáneo de Vargas fue el fotógrafo, editor e impresor quiteño José Domingo Laso (Ecuador), quien llegó a producir, entre 1899 y 1927, un número incalculable de tarjetas postales con paisajes, costumbres y tipos de Quito y alrededores (Laso, 2016, p. 79). Desde su Taller de Fotografía y Fototipia, Laso impulsó proyectos editoriales como la fundación de la revista de ciencias, artes y letras La Ilustración Ecuatoriana en 1909 (Laso, 2016, p. 65), y publicó cinco libros de fotografía dedicados principalmente a Quito entre 1911 y 1924 (Laso, 2016, p. 29).

Podemos encontrar un modelo básico de actuación profesional en Vargas, Gismondi y Laso, pero es evidente que los tres coinciden en el espíritu entusiasta por registrar y difundir las características del mundo andino próximo a ellos, motivados también por el beneficio comercial. Como sostiene Laso en referencia a la fotografía latinoamericana contemporánea de estos fotógrafos, construir la historia de la fotografía con contenidos vernaculares andinos nos enfrenta inevitablemente con interrogantes sobre la identidad y a las formas de construir la historia (2016, p. 40).

Max T. Vargas, a través de su estudio de Arequipa, se convirtió en una referencia regional y fuente de divulgación visual preponderante. Además de las postales y vistas, fue colaborador de las publicaciones que el fotógrafo y editor portugués Manuel Moral fundó en Lima desde 1905 -las revistas Prisma, Variedades, 
Ilustración Peruana y el diario La Crónica en 1912-. Estas publicaciones dinamizaron las colaboraciones de fotógrafos del interior del país y favorecieron la visualidad nacional desde diferentes aspectos (Garay \& Villacorta, 2016).

En 1910, el diplomático y científico peruano Pedro Paulet dedicó un amplio reportaje a Max T. Vargas en la revista limeña Ilustración Peruana en el que lo calificó de "gran artista nacional" (Paulet, 1910). El artículo incluía fotografías de Tiahuanaco, paisajes del lago Titicaca, la costa de Mollendo, tipos andinos y retratos en estudio de damas arequipeñas. Ese es el tipo de fotografía con el que un profesional obtenía, en ese entonces y en ese contexto, un reconocimiento prácticamente consagratorio.

\section{Fotógrafos en Cusco a inicios del siglo $\mathrm{XX}$}

Como fotógrafo itinerante, Jacinto Gismondi regresó a Cusco en 1898, "trayendo un buen contingente de materiales de 1era clase" (J. C. Gismondi, 1898). Otro retorno suyo a Cusco se reporta en 1900 a través de un aviso publicitario de su estudio Fotografía Artística, ubicado en la calle Marqués, 100, en el que ofrecía "cualquier trabajo fotográfico" (Gismondi, 1900).

En 1900, el fotógrafo Francisco Guillén irrumpió en la fotografía cusqueña con su estudio Fotografía de Canchis, ofreciendo sus servicios profesionales de retratos a la clase burguesa de la ciudad con "los sistemas más modernos" (Guillén, 1900), ejecutados tanto en estudio como en los domicilios. Además, vendía máquinas fotográficas, vistas estereoscópicas, y hacía reducciones y ampliaciones. Se conoce que Francisco Guillén era de Arequipa, aunque estuvo asentado en Maranganí, provincia cusqueña de Canchis (De Bary Orihuela \& Kuon Arce, 2017, p. 16). Su archivo fotográfico está perdido, pero dejó su principal legado a la fotografía cusqueña a través de sus hijos Víctor (Maranganí, 1888 - Cusco, 1949) y Abraham (Cusco, 1901 - Lima, 1974).

Víctor fue un notable abogado cusqueño comprometido con el desarrollo de un sistema judicial. Por intermedio de los cargos que ocupó, legisló a favor de las condiciones de vida de los indígenas. De Bary Orihuela y Kuon Arce (2017) enfatizan en la dimensión social y humana de Víctor Guillén, además de en su vocación de maestro, expedicionario y fotógrafo aficionado. Con dominio técnico y composiciones bien logradas, Víctor fotografió libremente temas familiares, paisajes, caminos, puentes, indígenas, amigos, fiestas, edificios 
históricos, vías férreas y, en 1920, Machu Picchu (Ruinas del antiguo Perú, 1920). En 1936, recibió la medalla de oro en la categoría de aficionados en el concurso fotográfico organizado por la Inspección de Turismo y Propaganda del Concejo Provincial del Cusco; el primer premio profesional de este evento fue otorgado a Martín Chambi (Clausurose la exposición de arte fotográfico, 1936). La obra de Víctor Guillén atraviesa el primer tercio del siglo XX de la fotografía cusqueña con la novedosa práctica de aficionado.

La obra fotográfica de su hermano Abraham Guillén también resulta relevante para la construcción de la historia de los fotógrafos cusqueños. Al igual que Víctor, debió haber aprendido fotografía con su padre, pero se lo detecta activo en Lima como fotógrafo periodístico en los diarios El Sol y La Noche. Sin embargo, produjo su obra más importante cuando trabajó en el Museo Nacional hacia 1932, atendiendo el llamado del reconocido historiador y antropólogo cusqueño, promotor del indigenismo, Luis Valcárcel, quien asumiría la dirección de dicha institución. Abraham estuvo vinculado a instituciones del Estado para registrar el patrimonio cultural del Perú (Majluf \& Wuffarden, 2001, p. 66) y es considerado como "fotógrafo científico" por su trabajo de documentación en el territorio peruano y en proyectos arqueológicos de Max Uhle, Julio C. Tello y Luis Valcárcel (Gómez, 2007, p. 503). En la relación de los hermanos Guillén con su padre fotógrafo debió haber existido una transmisión de conocimiento importante en materia de fotografía.

El pintor, actor y fotógrafo Juan Manuel Figueroa Aznar, que había trabajado en Arequipa con Max T. Vargas entre 1902 y 1903, se estableció en Cusco en 1904. Este año, a través de un aviso publicitario, ofreció sus servicios fotográficos a la sociedad cusqueña en asociación con "el acreditado establecimiento del señor José Gabriel González”, situado en la calle del Triunfo, 96 (Rizo Patrón, 1904). En este aviso, Figueroa Aznar ofrece sus servicios de pintor, pues señalaba que su taller de pintura funcionaba en la misma dirección. Uno de los productos con los que Figueroa se hizo famoso fue el fotoóleo. Este fotógrafo y pintor tuvo una actividad intermitente, pero volvió a aparecer en Cusco en 1920.

José Gabriel González fue un fotógrafo cusqueño nacido en 1875. Trabajó en Fotografía Inglesa, un estudio a cargo, según Majluf y Wuffarden, del misionero protestante Thomas Penn, del que poco se sabe (2001, p. 64). González estuvo activo en Cusco hasta la década de los cuarenta, aproximadamente, y su nombre 
se menciona frecuentemente cuando se habla de la escuela de fotografía cusqueña, aunque no existe mayor información sobre su obra.

\section{Científicos, fotógrafos y divulgación}

El arqueólogo alemán Max Uhle utilizó la fotografía como un instrumento de registro de sus trabajos de excavación y de documentación propia sobre diversos temas. De hecho, Luis Valcárcel reconocería años después la labor científica de Uhle en el sur andino a inicios del siglo XX (Valcárcel, 2013). El interés por el pasado prehispánico de Uhle se remonta a 1892, cuando investigó en Tiahuanaco y publicó el libro Las ruinas de Tiahuanaco en las tierras altas del antiguo Perú con Adolph Stubel y fotografías de G. Von Grumbkow. También hizo estudios en Ecuador.

Además del uso instrumental de la cámara y los revelados que él hacía de sus placas negativas, Uhle fue coleccionista de fotografías, afición que fomentó entre sus pares alemanes que estaban trabajando en el continente americano. A su paso por Arequipa hacia Cusco entre 1905 y 1907 -dirigía el Museo de Historia Nacional del Perú- (Buchholz, 2017), adquirió un conjunto significativo de tarjetas postales y de vistas de Cusco y del sur peruano y norte boliviano en el establecimiento de Max T. Vargas. Como gran parte de los archivos documentales y fotográficos de Uhle y de otros científicos alemanes de la época - como los de Hans Steffen, Walter Lehmann y Eduard Seler- se ubican actualmente en el Instituto Iberoamericano de Berlín, esta institución conserva más de cien fotografías originales de Max T. Vargas sobre Cusco tarjetas postales en papel fotográfico y litográficas, y vistas en papel de bromuro de plata de 20 x $24 \mathrm{~cm}$ y otros tamaños- (Wolff, 2017). La presencia de fotografías de Vargas y de otros fotógrafos andinos en Berlín explica el valor que tuvo la imagen para los arqueólogos y etnógrafos alemanes. Las imágenes elaboradas para satisfacer un gusto consumista del turista y viajero funcionaban como fuentes de información para los científicos.

La relación entre científicos, el grabado y la fotografía tiene larga tradición en Centroamérica y los países andinos donde hubo expediciones interesadas por las antiguas culturas autóctonas. Navarrete ha hecho un recuento sucinto de viajeros y científicos, como George Squier, Charles Wiener, Alphons Stübel, Teobert Maler, Max Uhle (2009/2017, pp. 81-82), entre otros, "que revelaron al 
mundo la riqueza de las culturas prehispánicas [que] sirvieron a varias de las jóvenes repúblicas latinoamericanas para reivindicar una tradición como naciones que se remontaba más atrás de la presencia española" (2017, p. 83). Por la concentración en Cusco de vestigios arqueológicos, esta región también fue objeto de intereses científicos transnacionales, y generadora de un turismo andino y la consiguiente demanda por fotografías temáticas. Los fotógrafos se incentivaron ante las nuevas posibilidades del mercado de las fotografías e incorporaron temas cusqueños en sus repertorios. Modesto Chacón fue uno de ellos; llegó a Cusco en 1907, proveniente del pueblo de Sicuani -cercano a Cusco-, "con el objeto de tomar vistas de los monumentos incaicos y edificios modernos del Cuzco. También se dedica a la confección de retratos para particulares", en la calle de Maruri, 13 (Notas sociales, 1907).

No es casual que Max T. Vargas haya publicado en el periódico cusqueño, en 1909 y 1910, un aviso donde ofrecía "una colección notable y completa de ruinas, antigüedades, tipos, costumbres del Cusco, así como de Mollendo, Arequipa, Puno, Tiahuanaco, La Paz" (Vargas, 1909, 1910). En este anuncio, Vargas consignó las direcciones de su estudio de Arequipa y de La Paz (Bolivia). Coincidentemente, en la misma página de esta edición, se publicaron avisos publicitarios de Emilio Díaz (1910), fotógrafo retratista arequipeño de prestigio internacional que ofrecía sus servicios a los cusqueños que viajaban hacia Arequipa, y del fotógrafo Miguel Chani, establecido en Cusco, pero originario de Puno (Majluf \& Wuffarden, 2001, p. 50).

El inicio de la actividad de Chani se ha ubicado en septiembre de 1908 en el registro de licencias del Concejo Provincial del Cusco (1908). A principios de 1909, Chani anunció su estudio Fotografía Universal en la calle Bolívar, 39, donde vendía "hermosas colecciones de vistas incaicas del Perú, de Bolivia y de la inauguración del Ferrocarril" (Chani, 1909), en clara sintonía con el interés sobre culturas originarias. Pero la venta de fotografías de la primera llegada del ferrocarril a Cusco expresa una apertura al progreso y a lo novedoso.

En su aviso de 1910, en el que consignaba su estudio en la calle Marqués, $90-$ local que pasaría a manos de Figueroa Aznar, Julio Acevedo y Martín Chambi entrada la década de los veinte-, anunciaba que fotografiaba bautizos, matrimonios, fallecimientos o cualquier otro evento para el cual "solicite $\mathrm{U}$. [usted] el rápido servicio de nuestros expertos fotógrafos. No pierda estas 
oportunidades, pasado un tiempo las fotografías de estos acontecimientos representan un valor incalculable" (Chani, 1910). Si Chani contaba en la organización empresarial de su estudio con fotógrafos expertos a los que él encargaba fotografiar eventos, es probable que la atribución de ser él, como lo señalan Trevisan y Massa, uno de los fundadores de la escuela cusqueña de fotografía encuentre en este aviso un elemento que lo sustente (2009, p. 53), siempre y cuando se determine quiénes fueron los fotógrafos que trabajaron con él y la influencia que ejerció sobre ellos.

Chani también colaboró con medios de comunicación limeños como la revista Ilustración Peruana (Jura de la bandera por el Regimiento, 1910). De hecho, Chani ejerció el modelo de "profesional de la imagen" (Trevisan \& Massa, 2009, p. 55) para el Cusco del momento: fue retratista, documentó provincias cusqueñas y bolivianas, y vendió vistas y postales de arqueología, paisajes y temas de actualidad.

El hallazgo en 1911 de Machu Picchu por el estadounidense Hiram Bingham, que contó con expediciones respaldadas por la Universidad de Yale y la National Geographic Society, contribuyó a poner a Cusco en el centro del interés internacional gracias a la publicación, en abril de 1913, de una edición especial de The National Geographic Magazine. Bajo el título In the wonderland of Peru (Bingham, 1913), la edición publicó 244 fotografías de la expedición, que mostraban el valle de Urubamba y Machu Picchu, andenerías, estructuras y vistas panorámicas; se incluyeron mapas, y fotografías de las excavaciones, escaleras, muros y detalles de arqueología. Se presentaba a Machu Picchu cubierto por densa vegetación. Todo parece haberse construido visualmente para remarcar las huellas irrefutables de una civilización pasada, pero, como señala Gómez, las imágenes y representaciones de ciudades perdidas, como Machu Picchu, "pasaron a ser parte de la nueva sociedad de consumo" (2007, p. 502). The National Geographic Magazine se había posicionado como un medio divulgador de hallazgos de culturas originarias, utilizando la fotografía como un recurso preponderante.

Por ese entonces, la postal, un producto económico y eficiente (Riego, 2011, p. 4), estaba siendo popularizada en el sur andino peruano desde la década anterior al hallazgo de Machu Picchu. Fotógrafos como Vargas en Arequipa, Gismondi en Bolivia, Laso en Quito y Chani en Cusco producían y vendían sus 
postales desde años anteriores, lo que fomentaba, como señala Riego, el coleccionismo como práctica social y expresión de tiempo moderno (2011, p. 14).

Aun así, hubo que esperar a la década de los veinte para tener postales de Machu Picchu, porque el acceso era muy difícil y peligroso. Recién en 1920 el diario limeño La Crónica publicó en su portada, como se señaló, la noticia "Ruinas del Antiguo Perú" (1920), con dos fotografías de Víctor Guillén que mostraban dos espacios de Machu Picchu con abundante vegetación.

Al mismo tiempo que Machu Picchu se hacía público, en el Cusco había una movimiento académico e intelectual interesante. En 1911, Uriel García defendió la tesis El arte incaico en el Cuzco, y se convirtió en el primer académico cusqueño, según Kuon Arce, Gutiérrez Viñuales, Gutiérrez y Viñuales, en ocuparse del tema inca en una universidad local (2009, p. 44). Por otro lado, en 1912, el rector de la Universidad Nacional de San Antonio Abad del Cusco, Alberto Giesecke, fundó la Revista Universitaria; en 1913, Luis Valcárcel y José Caparó fundaron el Instituto Histórico del Cusco, convocando a otros intelectuales cusqueños contemporáneos con el propósito de "impulsar los estudios históricos, arqueológicos y folclóricos" de la región (Kuon Arce et al., 2009, p. 29). Desde la historia, la arqueología, la antropología y la etnografía, se abordaron la historia y el patrimonio colonial y prehispánico.

Sin que apareciera el indigenismo de manera nominal, durante la década de 1910 se analizó y discutió el tema de la raza, lo cual planteó el desafío de compatibilizar las cuestiones indígenas con el desarrollo material que experimentaba Cusco. Las nuevas rutas de acceso del ferrocarril, las líneas del tranvía, la hidroeléctrica de Qorimarka y los comercios textiles -entre otras actividades- contribuyeron a dinamizar la economía local (Kuon Arce et al., 2009, p. 27). Los fotógrafos registraron estos cambios y los contrastes que se daban con la vida de los indígenas tanto en la ciudad como en los pueblos.

\section{Los fotógrafos activos en Cusco en 1920 y la llegada de Martín Chambi}

En una noticia de diciembre de 1919, el fotógrafo José Gabriel González viajaba a Chiñicara (Oropesa) como "jefe de la sección gráfica" del diario El Comercio. Esta noticia también informaba que Figueroa Aznar llegaba a Cusco desde 
Paucartambo y que iba a establecer "su oficina fotográfica en esta ciudad, para la que cuenta con una espléndida galería en la calle del Marqués" (De viaje, 1919). Por su parte, el fotógrafo Miguel Chani, activo desde 1908, publicó un aviso en esta edición en el que anunciaba que su estudio fotográfico se había trasladado a la calle Qquera, 44; es decir, había desechado trabajar en el estudio de la calle Marqués (Chani, 1919).

Desde enero de 1920 hasta gran parte del año 1921, Juan Manuel Figueroa Aznar ocupó el estudio de la calle Marqués, 67; el que había sido utilizado por Chani. Este local representó para el fotógrafo un importante reposicionamiento artístico y comercial: ofrecía fotografía artística, tarjetas postales, vistas de Cusco, ampliaciones y revelados de películas. Además, brindaba sus servicios en "Pintura", con ampliaciones iluminadas a la acuarela o al pastel, paisajes de la región, cuadros históricos, retratos al natural y fotoóleo (Figueroa Aznar, 1920). $\mathrm{Al}$ otro extremo de la fotografía artística, encontramos una convocatoria pública del Ejército solicitando "propuestas para retratar al personal de tropa de la IV División. Las bases para este contrato podían verse en el local de la Sub Intendencia de Guerra, calle del Teatro No. 7" (Sub-Intendente de la IV División, 1920). Una imagen de José Gabriel González que custodia la Fototeca Andina de Cusco en la que se ven dos filas de soldados indígenas de perfil semidesnudos y rapados sobre fondos de telas podría haber sido resultado de esta convocatoria (Espinar, 2006, p. 19).

El artículo "El Cusco: Meca del Turismo de la América del Sur" de Alberto Giesecke (1921a, p. 3), elaborado en 1920, pero publicado en 1921 en la Revista Universitaria -y que se reeditó, con algunas variantes e incluso en idioma inglés, en guías turísticas sobre Cusco editadas en Lima-, es crucial para cerrar el marco temporal de esta propuesta, porque incluye la lista de fotógrafos activos dentro de una descripción detallada del Cusco histórico como un lugar extraordinario para los turistas y viajeros en general. En el apartado "Lo que puede comprar el turista", se señala que en los estudios de los siguientes fotógrafos se venden "tarjetas postales y vistas fotográficas del Cusco": Héctor G. Rozas -más conocido como impresor-, Miguel Chani, Juan Manuel Figueroa Aznar, José Gabriel González, Martín Chambi y Julio Acevedo. El autor resalta en este artículo que la colección de Miguel Chani de "ochenta vistas distintas es especialmente valiosa" (1921a, p. 12). 
En la Guía General del Sur del Perú, una edición especial publicada por el centenario de la Independencia del Perú en 1921, que reunió y divulgó ampliamente la actividad comercial de Arequipa, Puno y Cusco, se incluyó este artículo de Giesecke a modo de introducción, pero omitiendo a Chambi y a Acevedo (1921b, p. 9). Dos páginas ocuparon la publicidad del Estudio de Arte de Figueroa Aznar, incluyendo fotografías de "tipos de indígenas" realizadas en estudio (Figueroa Aznar, 1921, p. 189).

Esta nueva oferta fotográfica en Cusco representa la continuidad de una cultura fotográfica que había empezado a gestarse en la esfera pública cusqueña desde 1897 en la "Exposición General Departamental". Recordemos que fue Max T. Vargas -que arribó a Cusco a fines de 1920 con fines desconocidos (Notas sociales. Llegadas, 1920) - quien empezó a difundir, desde fines del siglo XIX, vistas y postales de temática arqueológica, indígena y monumental.

Además, los fotógrafos del grupo de Giesecke proveían de fotografías a los medios de comunicación impresos nacionales y extranjeros, y a editores de guías y publicaciones no periódicas (Hiatt, 2015, p. 298). La fotografía y el turismo cumplieron un rol importante en la proyección de Cusco hacia el mundo, pero las imágenes también estaban disponibles para los indigenistas, artistas, periodistas y científicos, locales y foráneos.

De esta lista de fotógrafos, Martín Chambi se convirtió rápidamente en el fotógrafo más importante. Cuando arribó a Cusco en 1920, encontró una competencia fuerte entre fotógrafos que estaban prácticamente consagrados. Chambi se presentó ante la sociedad cusqueña a través de un aviso publicitario de marzo de 1921, en el que enfatizaba que "después de muchos años de práctica en la Fotografía de los SS. Vargas Hnos. de Arequipa, tengo el honor de ofrecer mis servicios profesionales en el arte fotográfico en general" (Chambi, 1921).

Lo aprendido en Arequipa con Max T. Vargas entre 1908 y 1912, y en el estudio de los Vargas Hermanos -Carlos y Miguel fueron también asistentes de Max T., y no eran parientes- entre 1912 y 1917 fue determinante. Chambi estaba preparado técnica y conceptualmente en "arte fotográfico" para hacer retratos de estudio y en exteriores, para manejar el estudio fotográfico como una empresa, para participar en exposiciones artísticas individuales y colectivas y en concursos, para internacionalizar su obra y para colaborar con periódicos y revistas. Además, con su propia mirada documentó la diversidad cultural y la 
vida en los Andes, produjo y sistematizó miles de postales, manejó la dialéctica de la luz y de la sombra como recurso expresivo, y dominó las técnicas de copiado y el laboratorio.

Apenas se había instalado en Cusco en 1920, ya había producido "un inmenso surtido de postales y vistas del Cusco", como lo señaló en su aviso de 1921 (Chambi, 1921). Desde 1918 en Sicuani, como apunta Schwarz (2007), empezó sus colaboraciones con la revista Variedades y el diario La Crónica de Lima, tal como lo había visto hacer a Max T. Vargas. Chambi implantó y perfeccionó en Cusco el modelo de fotografía profesional que había aprendido en Arequipa (Garay \& Villacorta, 2020). Su origen étnico le permitió interpretar de manera original la complejidad andina, abarcando lo antiguo y también la apertura al desarrollo de Cusco.

Chambi supo que la sostenibilidad comercial y su prestigio de artista de la fotografía se lograrían con la conservación de su propio archivo fotográfico. Sabía lo que Miguel Chani mencionó en 1910 respecto al valor incalculable de la fotografía con el paso del tiempo, en el sentido de lo que señala Argerich: "el transcurso del tiempo dota a sus imágenes de valor histórico, testimonio de la vida material de los objetos y de las transformaciones sociales, con lo que adquieren una nueva posible lectura y dimensión" (2015, p. 110). De hecho, una razón por la que se conoce ampliamente la obra de Chambi en la actualidad es porque sus descendientes han sabido conservar y gestionar el archivo fotográfico, con documentación de época incluida, que él les heredó. No existen en Cusco archivos fotográficos completos de fotógrafos de la lista de Giesecke, circunstancia que ha limitado seriamente las investigaciones sobre la fotografía cusqueña.

\section{Conclusiones}

En el período delimitado entre 1897, año de la "Exposición General Departamental" y de la llegada de Max T. Vargas a Cusco, y 1920, año en el que Alberto Giesecke escribe el artículo "El Cuzco: Meca del Turismo de la América del Sur" - publicado luego en la Revista Universitaria y en la Guía General del Sur del Perú - y el arribo de Martín Chambi a la ciudad, hubo varios fotógrafos profesionales activos en Cusco. Durante estos años, la fotografía profesional se desarrolló bajo la modalidad que articulaba la figura individual, cuyo nombre se 
convierte en una marca comercial y de renombre artístico; un local o estudio como centro de operaciones; y la presencia en periódicos y revistas de avisos publicitarios que anunciaban diversos productos y servicios, como retrato, vistas y postales, revelados, entre otros. Los fotógrafos eran conscientes del valor del archivo fotográfico y, además, colaboraban con periódicos y revistas. Incluso, competían por reconocimiento y por el favor del público y la prensa local.

El hecho de que en 1897 la fotografía profesional fuera premiada y reconocida por la prensa local y en la esfera pública contribuyó, desde entonces, a gestar una cultura fotográfica en Cusco. En ese contexto, el fotógrafo arequipeño Max T. Vargas, con su trabajo temprano realizado en esta ciudad durante cuatro meses, y con la información de los avisos publicitarios que publicó sistemáticamente en diarios cusqueños entre 1909 y 1910, delineó y consolidó esas características del fotógrafo profesional.

Miguel Chani se estableció en Cusco en 1908 siguiendo ese patrón, pero, además, tuvo a su cargo a fotógrafos que lo ayudaban a atender la demanda de retratos. Hallar sus nombres y sus actividades contribuiría a repensar de manera novedosa la existencia de una escuela cusqueña de fotografía. Con investigaciones futuras, se podrá reconstruir la dimensión real de la obra de Chani, la cual coincide con momentos importantes de Cusco en la década de 1910, como las primeras tesis universitarias y publicaciones académicas de intelectuales notables - como Uriel García y Luis Valcárcel, entre otros- con aportes al indigenismo, la arqueología y la historia cusqueña.

Coincidentemente, en 1911 se produjo el hallazgo de Machu Picchu, lo que intensificó los análisis y discursos sobre la identidad e historia locales. Este acontecimiento, de repercusión internacional gracias a las fotografías que Hiram Bingham hizo y difundió, sirvió para poner en valor los sitios arqueológicos de la región. La fotografía científica, con los trabajos de Max Uhle y Hiram Bingham, se insertó en la historia de la fotografía cusqueña, y con ello también el coleccionismo de fotografías. La fotografía cusqueña se vio enriquecida por la actividad de fotógrafos profesionales, científicos o aficionados en momentos en que se requería fotografiar y divulgar las riquezas antiguas que se revelaban.

La presencia de la postal -y las vistas- atraviesa el rango de nuestro estudio, debido a los intereses comerciales de los fotógrafos, la eficacia del formato en 
circulación y visualización y la progresiva demanda turística. Merecería una investigación acotada, pero se evidencia que este producto fue creciendo en popularidad, tal como ocurrió contemporáneamente en La Paz o en Quito, especialmente por los contenidos relacionados con sitios arqueológicos, arquitectura colonial, tipos, costumbres y paisajes andinos.

Los antecedentes del ejercicio profesional del grupo de fotógrafos activos en Cusco en 1920 se remontan a 1897. Desde entonces, en la historia de la fotografía cusqueña y del sur andino peruano, aun cuando es necesario seguir investigando en las actividades y producción de los fotógrafos referidos, se evidencia, a la luz de este estudio, una práctica fotográfica profesional en boga.

\section{Referencias bibliográficas}

Argerich, I. (2015). Fotografía y archivo. Fotocinema. Revista Científica de Cine y Fotografia, (10), 101-117. Recuperado de https://revistas.uma.es/index.php/fotocinema/article/view/5981/5486

Benavente García, A. (2000). The Cusco School: Photography in Southern Peru, 1900-30. History of Photography, 24(2), 101-105. doi:10.1080/03087298.2000.10443376

Bingham, H. (abril de 1913). In the wonderland of Peru. The National Geographic Magazine, 24(4).

Buchholz, A. (2015). Las imágenes de Max T. Vargas en archivos científicos alemanes y su relación con la construcción visual de identidades y espacios del Sur Andino a principios del siglo XX. En A. Garay (Ed.), Fotografia Max T. Vargas. Arequipa y La Paz (pp. 9-50). Piura: Universidad de Piura.

Buchholz, A. (2017). Pasado y presente entrelazado: el Cusco en la mirada del científico alemán Max Uhle (1905-1907). En A. Garay (Ed.), Cusco revelado. Fotografias de Max T. Vargas, Max Uhle y Martín Chambi (pp. 67-127). Piura y Berlín: Universidad de Piura; Instituto Iberoamericano de Berlín.

Chambi, M. (14, 16, 18 de marzo de 1921). Fotografía Chambi [Aviso publicitario]. El Comercio, p. 4.

Chani, M. (9 de enero de 1909). Fotografía Universal en la calle Bolívar No. 39 [Aviso publicitario]. El Comercio, p. 1.

Chani, M. (7 de junio de 1910). Miguel Chani. Director y propietario de la Fotografía Universal [Aviso publicitario]. El Comercio, p. 10.

Chani, M. (27 de diciembre de 1919). Miguel Chani. Fotógrafo [Aviso publicitario]. El Comercio, p. 2.

Clausurose la exposición de arte fotográfico. (10 de enero de 1936). El Comercio, p. 2. 
Concejo Provincial del Cusco. (1908). Relación de licencias concedidas (Legajo 48, 1909). Archivo Histórico de la Biblioteca Municipal del Cusco.

De Bary Orihuela, U. \& Kuon Arce, E. (2017). Lente y sensibilidad. Miradas del Cuzco antiguo. Víctor Manuel Guillén Melgar. Cusco: Úrsula de Bary.

De viaje. (27 de diciembre de 1919). El Comercio, p. 2.

Díaz, E. (7 de junio de 1910). Fotografía de Emilio Díaz. El Comercio, p. 10.

Editorial. (21 de agosto de 1897). El Comercio, p. 2.

El Cuzco y su exposición industrial. (18 de setiembre de 1897). La Bolsa, p. 2.

Espinar, A. (2006). Fototeca Andina. 1900-1950. Lima: Centro Cultural PUCP.

Exposición Industrial. (18 de noviembre de 1896). La Bolsa, p. 2.

Figueroa Aznar, J. M. (19 de febrero de 1920). Estudio de Arte. Figueroa Aznar [Aviso publicitario]. El Comercio, p. 1.

Figueroa Aznar, J. M. (1921). Estudio de Arte Figueroa Aznar [Aviso publicitario]. Guía General del Sur del Perú. Cusco: Ed. H. G. Rozas y Sociedad de Propaganda del Sur del Perú.

Fotografía. (17 de febrero de 1897a). El Comercio, p. 2.

Fotografía. (16 de enero de 1897b). El Comercio, p. 4.

Fotógrafo. (29 de mayo de 1897a). El Comercio, p. 3.

Fotógrafo. (14 de agosto de 1897b). El Comercio, p. 3.

Fotógrafo. (11 de octubre de 1897c). El Comercio, p. 3.

Garay, A. \& Villacorta, J. (2016). El origen y desarrollo de la noción del "reportero gráfico" en el Perú y la visualidad del territorio a inicios del siglo XX. Diálogo Andino. Revista de Historia, Geografía y Cultura Andina, (50), 99-113. Recuperado de https://scielo.conicyt.cl/pdf/rda/n5o/arto8.pdf

Garay, A. \& Villacorta, J. (2020). La fotografía en Arequipa (1890-1930): definición y usos regionales de la imagen. En A. Garay \& J. Villacorta (Eds.), Guillermo Montesinos Pastor. Fotografía. 1916-1924 (pp. 22-35). Lima: KWY.

Giesecke, A. (1921a). El Cuzco: Meca del Turismo de la América del Sur. Revista Universitaria, (35), 3-17.

Giesecke, A. (1921b). El Cuzco: Meca del Turismo de la América del Sur. Guía General del Sur del Perú. Cusco: Ed. H. G. Rozas y Sociedad de Propaganda del Sur del Perú.

Gismondi, J. C. (4 de enero de 1897). Fotografía Artística [Aviso publicitario]. El Comercio, p. 4.

Gismondi, J.C. (19 de marzo de 1898). El Comercio, p. 2.

Gismondi, J. C. (5 de marzo de 190o). Fotografía Artística [Aviso publicitario]. El Comercio, p. 4.

Gómez, L. (2007). Machu Picchu reclamada. Viajes y fotografías de Hiram Bingham, Abraham Guillén y Martín Chambi. Revista Iberoamericana, 
73(220), 497-513. Recuperado de https://revistaiberoamericana.pitt.edu/ojs/index.php/Iberoamericana/article/view/53 $41 / 5498$

Guillén, F. (4 de agosto de 1900). Fotografía de Canchis [Aviso publicitario]. El Comercio, p. 4.

Gutiérrez, C. (6 de diciembre de 2017). Fiesta de la imagen. El Comercio, 2-3.

Hiatt, W. (2015). Andinos y aeroplanos: historia, tecnología e identidad a través del lente de Martín Chambi. En N. Majluf y E. Ranney (Eds.), Chambi (pp. 295-309). Lima: Museo de Arte de Lima.

Jura de la bandera por el Regimiento No. 1, 1910. (29 de junio de 1910). Ilustración Peruana.

Kuon Arce, E., Gutiérrez Viñuales, R., Gutiérrez, R., \& Viñuales, G. M. (2009). Cuzco - Buenos Aires. Ruta de intelectualidad americana (1900-1950). Lima: Universidad de San Martín de Porres.

Laso, F. (2016). La huella invertida: antropologías del tiempo, la mirada y la memoria. La fotografía de José Domingo Laso 1870-1927. Montevideo: Centro de Fotografía de Montevideo.

Majluf, N. (2015). Martín Chambi, fotografía e indigenismo. En N. Majluf y E. Ranney (Eds.), Chambi (pp. 3-27). Lima: Museo de Arte de Lima.

Majluf, N. \& Wuffarden, L. (2001). Índice documentado de fotógrafos activos en el Perú 1842-1942. En N. Majluf y L. Wuffarden (Eds.), La recuperación de la memoria. El primer siglo de la fotografía. Perú 1842-1942. Lima: Museo de Arte de Lima; Fundación Telefónica.

Navarrete, J. A. (2017). Fotografiando en América Latina. Ensayos de crítica histórica (2. ${ }^{\mathrm{a}}$ ed.). Montevideo: Centro de Fotografía de Montevideo.

Notas sociales. (21 de marzo de 1907). El Comercio, p. 2.

Notas sociales. Llegadas. (16 de diciembre de 1920). El Comercio, p. 3.

Nieto, L. (2008). La escuela cuzqueña de fotografía. Moment, (3), 12-16.

Paulet, P. (5 de octubre de 1910). Max T. Vargas. Un gran artista fotógrafo nacional. Ilustración Peruana, (53), 533-539.

Premios. (14 de setiembre de 1897). El Comercio, p. 1.

Programa para la Exposición General Departamental. (6 de marzo de 1897). El Comercio, pp. 2-3.

Querejazu Leyton, P. (2009). Luigi Doménico Gismondi. Un fotógrafo italiano en La Paz. La Paz: Pedro Querejazu L. Libros de fotografía No. 1.

Ramírez, A. (23 de junio de 1897). AR. Ramírez L. Fotógrafo [Aviso publicitario]. El Comercio, p. 4.

Riego Amézaga, B. (2011). Una revisión del valor cultural de la tarjeta postal ilustrada en el tiempo de las redes sociales. Fotocinema. Revista Científica de Cine y Fotografia, (2), 3-18. doi: 10.24310/Fotocinema.2011.voi2.5857 
Rizo Patrón, J. (5 de agosto de 1904). M. Figueroa y Aznar [Aviso publicitario]. El Comercio, p. 2.

Ruinas del antiguo Perú. (9 de octubre de 1920). La Crónica, p. 1.

Schwarz, H. (2007). Martín Chambi: corresponsal gráfico (1918-1929). En A. Castellote, A. Bryce, H. Schwarz, A. Garay, T. Allaín y J. M. Castro Prieto, Martín Chambi (pp. 31-44). Madrid: Fundación Telefónica; La Fábrica.

Sub-Intendente de la IV División. (10 de junio de 1920). Fotógrafos [Aviso publicitario]. El Comercio, p. 3.

Trevisan, P. \& Massa, L. (2009). Fotografías cusqueñas atravesando el indigenismo. Aisthesis, (46), 39-64. doi:10.4067/So71871812009000200003

Valcárcel, L. (2013). El imperio de los inkas y la unidad de la cultura andina. En J. L. Rénique (Ed.), Luis E. Valcárcel: del indigenismo cusqueño a la antropología peruana, 2 (pp. 688-707). Lima: Ediciones Copé Petroperú; Fondo Editorial del Congreso del Perú; Instituto de Estudios Peruanos.

Vargas, M. T. (18 de setiembre de 1909). Fotografía Max T. Vargas [Aviso publicitario]. El Comercio, p. 3.

Vargas, M. T. (7 de junio de 1910). Fotografía Max T. Vargas [Aviso publicitario]. El Comercio, p. 10.

Villacorta, J. \& Garay, A. (2017). Max T. Vargas, un joven fotógrafo arequipeño en Cusco en 1897. En A. Garay (Ed.), Cusco revelado. Fotografías de Max T. Vargas, Max Uhle y Martín Chambi (pp. 9-29). Piura y Berlín: Universidad de Piura; Instituto Iberoamericano de Berlín.

Wolff, G. (2017). Una memoria de América Latina en imágenes: la Fototeca del Instituto Ibero-Americano (IAI). En A. Garay (Ed.), Cusco revelado. Fotografias de Max T. Vargas, Max Uhle y Martín Chambi (pp. 183189). Piura y Berlín: Universidad de Piura; Instituto Iberoamericano de Berlín. 